\title{
Critical review of alkaline-polymer flooding
}

\author{
James J. Sheng ${ }^{1,2}$
}

Received: 1 November 2015/Accepted: 13 February 2016/Published online: 26 February 2016

(c) The Author(s) 2016. This article is published with open access at Springerlink.com

\begin{abstract}
Field performance shows that the incremental oil recovery factor from alkaline projects was low. Chemical EOR experience tells us that the mobility control is very important. Thus, the combination of alkaline flooding and polymer flooding is expected to improve alkaline flooding performance. This paper is to provide a critical review of alkaline-polymer (AP) flooding. The following subjects are covered.
\end{abstract}

- Interaction of alkali-polymer

- Technical screening criteria

- Laboratory and simulation work

- Summary of field projects

- Further discussion

The data and analysis presented in this paper will give readers updated information about alkaline-polymer flooding. This paper suggests the AP synergy need to be further studied with more experimental measurement, theoretical analysis and numerical simulation study.

Keywords Alkaline-polymer flooding · EOR · IOR · Alkali-polymer interaction · Synergy

\section{Introduction}

Although alkaline reaction with crude oil generates surfactants in situ, field performance shows that the incremental oil recovery factors from most of alkaline projects

James J. Sheng

james.sheng@ttu.edu

1 Texas Tech University, Lubbock, Texas, USA

2 Southwest Petroleum University, Chengdu, China were 1-2\% with a few projects having 5-6\% (Mayer et al. 1983; Sheng 2015). Polymer flooding provides the necessary mobility control for alkaline flooding, but it cannot reduce residual oil saturation because the capillary number cannot be significantly increased by high polymer viscosity in practice. Therefore, our intuition is that alkaline-polymer flooding will provide a synergy of alkaline flooding and polymer flooding. This paper will address this synergy and alkaline-polymer interactions, discuss the technical screening criteria, summarize field performance.

\section{Alkali-polymer interactions}

Alkali will accelerate polymer (polyacrylamide) hydrolysis. Thus polymer solution viscosity will increase in the first few hours of contact with alkali. But polymer solution viscosity quickly decreases because of the increase in ionic strength due to the existence of alkali (Sheng et al. 1994; Kazempour et al. 2012). It is commonly stated that the high $\mathrm{pH}$ from alkali makes polymer solution viscosity decreased. Actually, the decrease is not much caused by $\mathrm{pH}$ effect, as $\mathrm{pH}$ does not increase significantly when the alkaline concentration is increased (Kazempour et al. 2012). When adding an alkali in a polymer solution, there are two effects: increased ionic strength and $\mathrm{pH}$. Increased ionic strength reduces the polymer solution viscosity. At a high $\mathrm{pH}$, more carboxylate groups are converted. The negative carboxylate groups exert high negative repulsion, resulting in a higher polymer solution viscosity. However, the effect of increased ionic strength is more significant than the high $\mathrm{pH}$ effect. Generally, adding alkali will reduce polymer solution viscosity. We generally consider that polymer viscosity decreases with alkaline concentration (Kang 2001). Actually, the alkaline effect on polymer 
viscosity is complex, and the effect depends on polymers, alkalis, and pH (Shupe 1981).

Recently, Kamempour et al. (2012) presented an interesting data and interpretation on residual resistance factor. They observed that the residual resistance factor after AP flooding was much higher than that after polymer flooding. Their interpretation was that during post-AP brine flooding, the ionic strength was significantly reduced, and the polymer viscosity was restored. A question is, during postpolymer brine flooding, the ionic strength was also reduced, why was the residual resistance factor during post-polymer brine flooding not so high? Another question is, the residual resistance factor is caused by polymer adsorption. If the polymer adsorption during the AP flooding was lower than the polymer flooding, the residual resistance factor during post-AP brine flooding should be lower than that during post-polymer brine flooding. Kazempour et al.'s experimental observation needs to be confirmed by more experiments. If confirmed, a proper interpretation needs to be sought. In the opinion of the author of this paper, the high residual resistance factor during post-AP brine flooding may be caused by emulsion trapping.

To overcome the problem that the polymer viscosity decreases in alkaline solution, a new co-polymer P(AAc-stVP) was synthesized using acrylic acid (AA) and $N$-vinyl-2pyrrolidinone (NVP) and a proper initiator (Doda et al. 2013). The new co-polymer can be stable in alkaline solution.

Laboratory test results show that alkaline consumption in an alkaline-polymer system is lower than in the alkaline solution alone. This is probably because polymer covers some of rock surfaces to reduce alkali-rock contact. In an alkaline-polymer system, alkali creates a high $\mathrm{pH}$ environment and thus alter the charge density on the rock surface to more negative charge. As a result, polymer adsorption is reduced (Krumrine and Falcone 1987; Chen et al. 1999; Kazempour et al. 2012). These interactions are less discussed in the literature.

Figure 1 shows the recovery factors of waterflood residual oil in different combinations and sequences of injection of polymer and orthosilicate (Krumrine and Falcone 1983). In the figure, $\mathrm{A} / \mathrm{P}$ represented the sequence of alkali injection followed by polymer injection, P/A was the sequence of polymer injection followed by alkali injection, and $\mathrm{A}+\mathrm{P}$ meant the alkali and polymer was injected at the same slug. The results show that any sequence was better than a single component injection, and the combination of alkali and polymer offered the highest oil recovery that was higher than the sum of those from alkali flooding alone and polymer flooding alone. The synergy of alkali and polymer was clearly demonstrated. Similar results were also obtained by Sheng et al. (1994) and Chen et al. (1999).

Alkali also reacts with naphthenic acids in the crude oil to generate surfactants in situ (generally named soap)

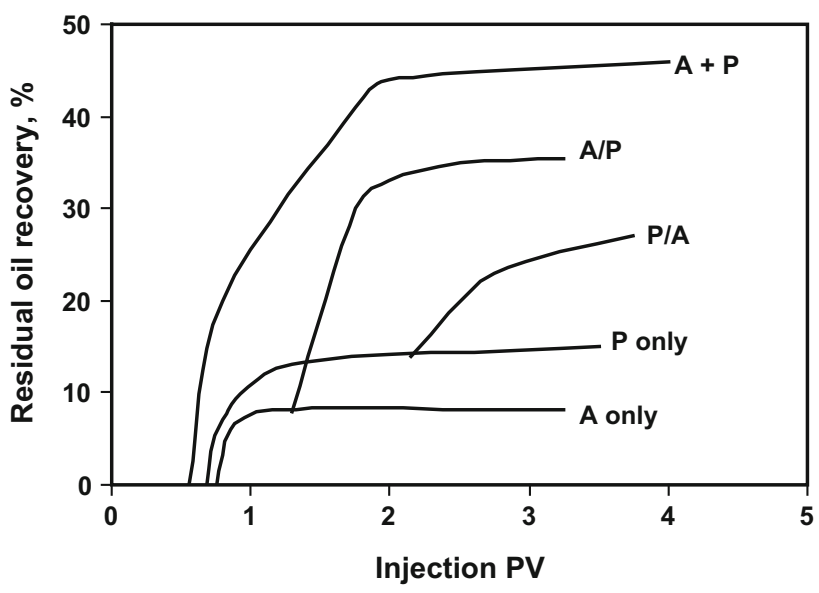

Fig. 1 Comparison of coreflood residual oil recovery factors polyacrylmide and orthosilicate

(Ehrlich and Wygal 1977). Soap, a surfactant, reduces interfacial tensions and thus reduces residual oil saturation. Polymer provides mobility control for the alkaline solution. Therefore, alkaline-polymer can provide a synergy to improve oil recovery. These is no consensus regarding the polymer effect on alkali/oil interfacial tension (IFT). Generally, it is believed that polymer has little effect on the IFT.

The synergy between alkali and polymer flooding may be summarized as follows.

- Alkali in an alkaline-polymer solution can reduce polymer adsorption and polymer can reduce alkaline consumption.

- Polymer makes the alkaline-polymer solution more viscous to improve sweep efficiency. Thus, polymer "brings" alkaline solution to the oil zone where the alkali cannot go without polymer. More oil can be displaced by lowered IFT owing to alkali-generated soap. In other words, alkali and polymer work together to improve both sweep efficiency and displacement efficiency.

- The alkaline-polymer environment may decrease biodegradation.

- Alkali may reduce polymer viscosity due to the increased salt from added alkali (Sheng et al. 1994; Kang 2001). This is a negative effect. However, in tight formation, this effect may help improve injectivity near the wellbore region.

\section{Technical screening criteria}

No paper was published to specifically address the technical screening criteria for alkaline-polymer (AP) flooding except Al-Bahar et al. (2004). But several authors proposed 
the screening criteria for separate alkaline flooding or polymer flooding. The criteria for AP from Al-Bahar (2004) and the criteria for separate alkaline flooding and polymer flooding are listed in Table 1. Each parameter from field alkaline flooding, polymer flooding and AP flooding projects are also listed. The parameter values are generally the medians of their respective parameters from field projects. Finally, new criteria for AP flooding are proposed as shown in Table 1 as well.

\section{Laboratory and simulation work}

The laboratory work needs to be for alkaline flooding, polymer flooding and combined alkaline-polymer flooding. The laboratory work for polymer flooding is briefed in Sheng et al. (2015). The laboratory work for alkaline flooding is discussed in Sheng 2015. For alkaline-polymer flooding, we need to check the compatibility of alkali and polymer and conduct corefloods using the combined solution. We may also need to do comparative corefloods to check whether a combined solution is superior to alkaline solution alone or polymer solution alone in terms of incremental oil recovery.

A recent laboratory study was conducted to seek an AP application in a heavy oil reservoir (Wu et al. 2011). Heavy oil with a viscosity of $1202 \mathrm{cP}$ and an acid number of $1.07 \mathrm{mg} \mathrm{KOH} / \mathrm{g}$ oil and produced brine were used in their study. They found that the injected chemical solution within the high-permeability channels was diverted to lowpermeability zones. They stated that AP flooding was more efficient than either alkaline flooding or polymer flooding alone, but no data was shown. The optimal formulation used was $0.4 \% \mathrm{NaOH}+0.2 \% \quad \mathrm{Na}_{2} \mathrm{CO}_{3}+1000 \mathrm{ppm}$ polymer, with an incremental oil recovery of $25-30 \%$ of OOIP.

Most of reservoir simulators can reasonably catch the mechanisms of polymer flooding. The challenge to simulate alkaline-polymer flooding lies in alkaline simulation. The status of alkaline flooding simulation is updated by Sheng (2015).

\section{Summary of AP field projects}

Only eight field projects were found, four in Canada, two in China, and two in USA, as shown in Table 2. All field projects were carried out in sandstone onshore reservoirs. Most of the projects were limited in pilot areas, at high water cuts and high water saturations. Alkalis used were $\mathrm{Na}_{2} \mathrm{CO}_{3}$ in most of cases, and polymers were polyacrylamide type. For more details, see Table 2 and the listed references. No detailed data about alkaline-polymer

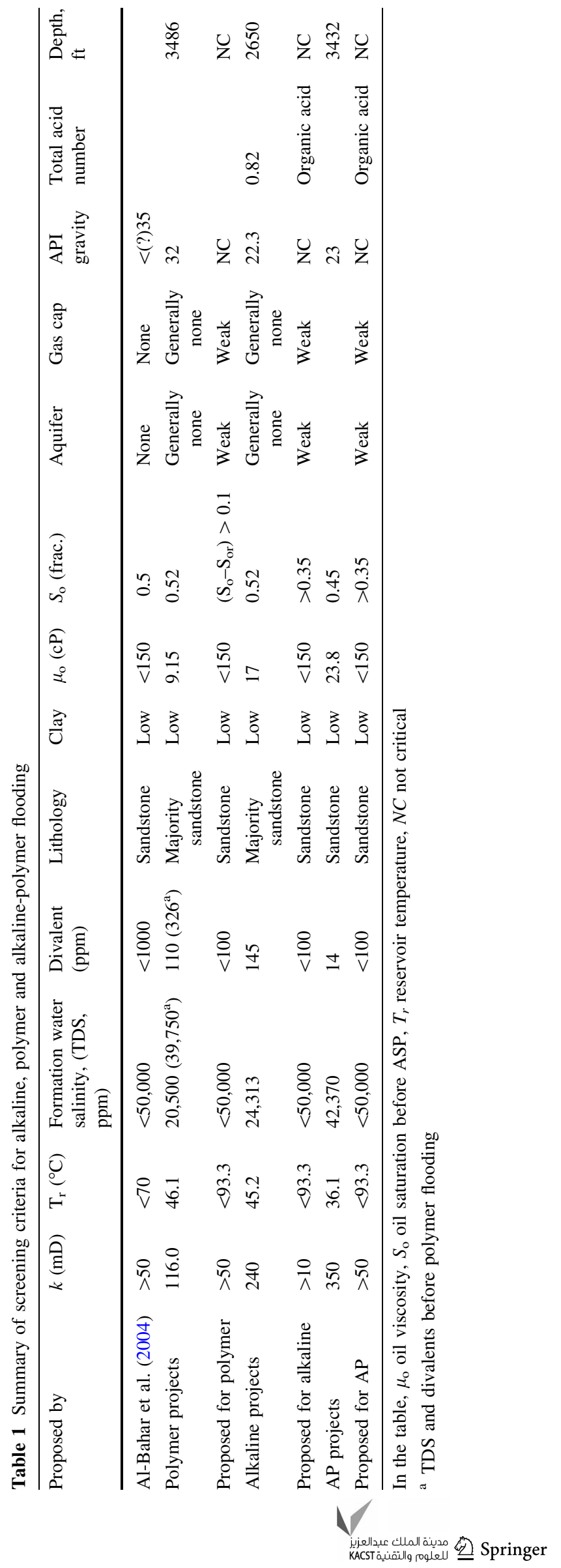




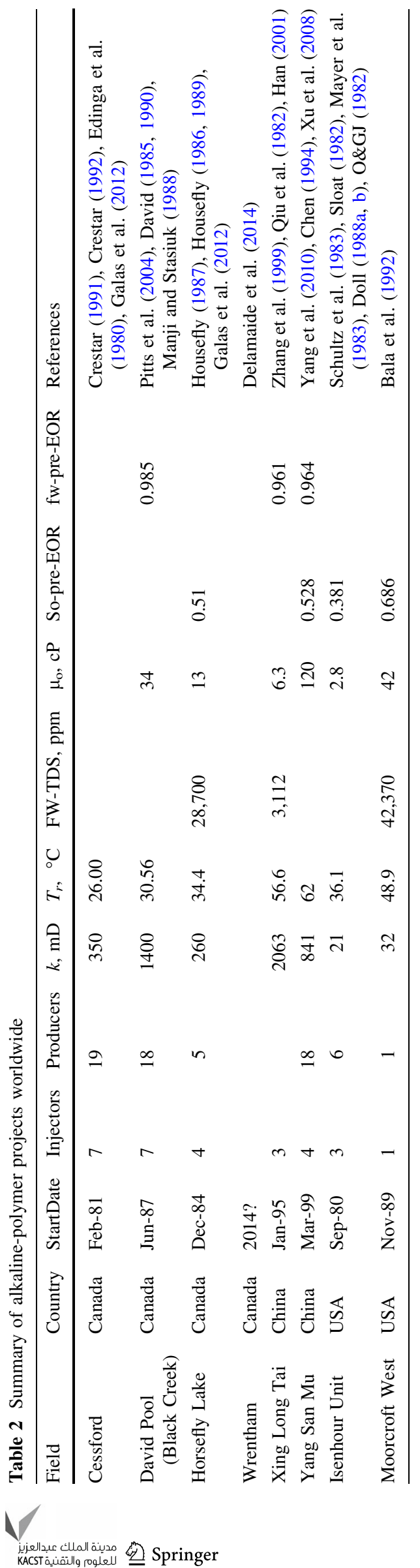

flooding projects in Russia or the former Soviet Union are available in the English literature. Shandrygin and Lutfullin (2008) listed 364 alkaline-polymer well treatments as "flow-diverting technologies" applications. The performance from these well treatments showed that an incremental oil of little bit over 1000 tons per well was obtained.

For AP projects, alkali and polymer must be injected in the same slug. Sometimes, a preflush of alkaline slug was injected. For the Almy Sands (Isenhour Unit) in Wyoming, a cationic polymer slug (0.05 PV at $215 \mathrm{ppm})$ was preflushed to provide a preferential blockage of high permeability channels in the predominantly anionic sandstone reservoirs (Doll 1988a, b). Such preflush is called the CAT-AN process (Sloat et al. 1972). Such process was also carried in the West Moorcroft AP project (Bala et al. 1992).

After a main AP slug is injected, polymer post-flush is followed before waterflooding in some cases. By doing so, the subsequent water will not finger into the AP slug.

The amount (median) of polymers injected from the surveyed projects was 1.7 (product of injection pore volume (PV) in \% and injection concentration in \%). This account is much lower than that used in modern Chinese polymer flooding projects alone which is about 4 . The median of alkalis was 16.2 (product of $\mathrm{PV}$ in $\%$ and concentration in \%). This amount is very close to that for surveyed alkaline flooding projects alone (Sheng 2015).

From the available data, the average incremental oil recovery factor was $14 \%$. The average decrease in water cut after AP injection was $12.5 \%$. Only two projects had economic data; the average was $\$ 1.7 / \mathrm{bbl}$ of incremental oil. All of these field projects are briefed next except Wrentham whose details are not available.

\section{Cessford Basal Colorado A}

The Cessford Basal Colorado A pool was a heavy oil sandstone reservoir at a depth of $920 \mathrm{~m}$. The oil gravity was $23^{\circ}$ API and oil viscosity was $24 \mathrm{cP}$. The acid number was $0.5 \mathrm{mg} \mathrm{KOH} / \mathrm{g}$ oil. The average porosity was 0.24 . The average permeability was $350 \mathrm{mD}$. The clay content was $4 \%$ almost all kaolinite. The reservoir temperature was $29^{\circ} \mathrm{C}$ (Edinga et al. 1980). The average water saturation before AP flooding was 0.30 .

Waterflooding commenced in the three areas in 1981. A preflush of softened salt water was injected from December 1983 to July 18 , 1984 when alkaline flooding (1\% $\mathrm{NaOH}+1.3 \% \mathrm{NaCl}$ ) commenced in the North and Central patterns. The preflush was to prevent alkaline solution to contact with hard water injected. The alkaline injection was converted to an alkaline-polymer flood in May 1985. An alkaline-polymer flood was started in the South area in January 1985. There was no period of preflush or caustic 
injection in the South area before alkali and polymer were injected.

The field performance showed poor injectivity at chemical injection wells. The poor injectivity resulted in no incremental oil production observed. The poor injectivity might be caused by precipitates that might occurred when the caustic solution contacted with the hard water injected before alkaline injection (but divalent concentrations in the injected water were not reported). It might be also caused by polymer adsorption and the reaction between caustic solution and formation clay (Galas et al. 2012). It was estimated that it would take more than 6 years to complete the placement of a $10 \%$ PV slug in each of the five injectors in the North and South areas. The reservoir could not wait six or more years for the chemical slug to be injected because a pressure gradient existed across the pool, caused by gas production in the east and water influx in the west. If the pressure in the oil zone was further depleted, the gas cap and the edge water would broke in. Therefore, the alkaline-polymer flood was terminated in the North and South areas in October 1990, and it was terminated in the Center area in February 1991.

\section{David Lloydminster 'A' pool}

An AP project was carried out in the David Lloydminster 'A' pool in the east central Alberta, Canada. The reservoir temperature was $30.6^{\circ} \mathrm{C}$. The oil viscosity at the reservoir temperature was $34.1 \mathrm{cP}$. The formation permeability was $1400 \mathrm{mD}$. The field was waterflooded with the oil recovery of $30 \%$ before AP injection. Lab tests were conducted to compare the performance AP with ASP and finally AP injection was selected. $0.213 \mathrm{PV}$ of $1 \mathrm{wt} \%$ sodium carbonate and 800 ppm Alcoflood 1175 polymer were injected, followed by tapered polymer concentration. The source water was treated and the final hardness was close to zero, and the TDS was about 6600 ppm (Manji and Stasiuk 1988). The injection was started in June 1987 and ended in December 1990. Total wells in the project were 7 injectors and 18 producers. The incremental oil recovery was $21 \%$ and the cost (including drilling cost) was $\$ 3.71 / \mathrm{bbl}$ of incremental oil (Pitts et al. 2004).

\section{Horsefly Lake Lower Mannville pool}

The Horsefly Lake Lower Mannville pool was a lightmedium oil sandstone reservoir at a depth of $964.3 \mathrm{~m}$. Four existing producers outside this pattern were also part of the pilot. The total pilot area including the four outside producers was about 13 ha. Cumulative injection totaled $43 \%$ pore volume; cumulative chase water injection was $16 \%$ pore volume. The pilot was completed in May, 1987. The total incremental oil recovered was $8 \%$ of the OOIP in the pilot area. However, Galas et al. (2012) concluded that the alkali/polymer flood did not work due to excessive adsorption caused by the high clay content of the reservoir. The improvement in the recovery was attributed to the closer well spacing. The reservoir was found to be more heterogeneous than expected, hence the benefit of the closer well spacing showed up.

\section{Xing Long Tai}

The pilot test was performed in the western part of the Xing-28 block in the Liaohe Oilfield. It had a gas cap and edge water. The formation porosity was 0.276 and the permeability was $2063 \mathrm{mD}$. The reservoir live oil had a density of $0.8174 \mathrm{~g} / \mathrm{cm} 3$ and viscosity of $6.3 \mathrm{cP}$ at the reservoir temperature of $56.6^{\circ} \mathrm{C}$. The formation water TDS was $3112 \mathrm{mg} / \mathrm{L}$ with $\mathrm{Ca}^{2+}$ and $\mathrm{Mg}^{2+}$ of $14 \mathrm{mg} / \mathrm{L}$. The central pilot area covered $0.037 \mathrm{~km}^{2}$ with a thickness of $7.4 \mathrm{~m}$. The rock had $6.3 \%$ carbonate content and $2.5 \%$ clay content. Before the AP pilot test, the water cut was $96.2 \%$, and the oil recovery was $46.75 \%$.This gas cap area was far away from the AP flooding area so that AP should not be affected by gas cap.

To select alkali, six alkalis, $\mathrm{NaOH}, \mathrm{Na}_{2} \mathrm{SiO}_{3}, \mathrm{Na}_{4} \mathrm{SiO}_{4}$, $\mathrm{Na}_{3} \mathrm{PO}_{4}, \mathrm{NaHCO}_{3}$, and $\mathrm{Na}_{2} \mathrm{CO}_{3}$, were used to compare IFT reduction, emulsification, alkaline consumption, and alkaline-polymer interaction. The final pick was $\mathrm{Na}_{2} \mathrm{CO}_{3} .8$ HPAM-type polymers were evaluated. The final selection was $1175 \mathrm{~A}$ based on its lower price. Core flood tests were used to compare polymer flood only and alkaline-polymer performance. A comparative simulation study was also carried out for alkaline flooding, AP flooding and alkalinesurfactant-polymer (ASP) flooding. Finally, AP was selected. And the final selected formula was $2 \% \mathrm{Na}_{2}$. $\mathrm{CO}_{3}+1000$ ppm 1175A.

After all the preceding studies were done, the AP pilot test was implemented from January 1995 to August 1998. The AP flood increased the oil recovery by $1.98 \%$ (OOIP) for the whole pilot area and $18.5 \%$ (OOIP) for the central well area, respectively. From January 1995 to the time the water cut reached $98.0 \%$, the oil recovery was $3.34 \%$ (OOIP) for the whole pilot area, and AP had contributed an ultimate oil recovery of about $50 \%$ (OOIP). However, it was found that the AP flood conducted in this pilot area was not economically attractive owing to larger amount of capital investment and the low oil price at that time.

\section{Yang San Mu}

This is an AP project in China with a high water-cut $(>96 \%)$, viscous oil (114 $\mathrm{cP}$ at the reservoir temperature 
$62{ }^{\circ} \mathrm{C}$ ), and the acid number of $1.84 \mathrm{mg} \mathrm{KOH} / \mathrm{g}$ oil (Yang et al., 2010). The pilot test program was run from 1999 to 2008. There were 4 injectors and 18 producers. The injection slug was divided into three phases: $0.16 \mathrm{PV}$ of $0.84 \% \mathrm{Na}_{2} \mathrm{CO}_{3}+1094 \mathrm{ppm}$ polymer (Pfizer 3430S), 0.06 $\mathrm{PV}$ polymer of $1441 \mathrm{ppm}$, and $0.03 \mathrm{PV}$ low polymer concentration. Water of TDS $1509 \mathrm{ppm}$ was used in mixing the AP solution. $\mathrm{NaOH}$ was changed to $\mathrm{Na}_{2} \mathrm{CO}_{3}$ because injection pumps had scale problem in the early phase. Produced water of TDS $5400 \mathrm{ppm}$ was re-injected (Chen 1994). Core tests showed AP could increase oil recovery factor by $22.8 \%$. After 6 month injection, residual oil saturation decreased from 52.8 to $39.6 \%$, and water cut decreased from 96.4 to $71.6 \%$. A stabilizer called $\mathrm{GH}$ was used to reduce polymer viscosity loss (Xu et al., 2008).

\section{Almy sands at Isenhour unit}

To reduce residual oil saturation, polymer-augmented alkaline injection was initiated in the Almy Sands at Isenhour Unit in Wyoming in 1985. Core studies showed abundant chlorite and kaolinite content. Migrating-fines problems associated with these clays were observed. Injection wells were pre-soaked with $\mathrm{KCl}$ for clay control. A cationic and anionic polyacrylamide spreadhead preceded the addition of the alkaline agent which was $\mathrm{Na}_{2-}$ $\mathrm{CO}_{3}$. A tripolyphosphate-anionic polymer blend was injected for long-term wettability control and alkaline slug stability. Oil rate inclined at about $27 \%$ per year after the start of the chemical injection. Predicted water-oil ratio (WOR) versus oil recovery was compared for a base-case waterflood, a polymer-only flood and the actual polymeraugmented alkali flood. The actual WOR was lower (Doll 1988b). The chemical cost for the produced oil after chemical injection (not incremental oil over water flooding) was $\$ 1.12 / \mathrm{STB}$.

\section{Moorcroft West Minnelusa sand unit}

The sand unit was a confined reservoir that provided an idea setting for evaluation of an EOR method. The reservoir temperature was $49{ }^{\circ} \mathrm{C}$. The reservoir porosity was $15.2 \%$, and permeability $114 \mathrm{mD}$. The formation water TDS was 42,370 ppm, and the hardness was $\mathrm{Ca}^{2+} 999$ ppm and $\mathrm{Mg}^{2+} 536 \mathrm{ppm}$.

Initially, water was injected to confirm well connection. A total of $4500 \mathrm{lbs}$. of cationic polymer at an average concentration of $606 \mathrm{ppm}$ and $1700 \mathrm{lbs}$. of anionic polymer at an average concentration of $284 \mathrm{ppm}$ were injected. Later AP was initiated with $\mathrm{KOH}$ as an alkali. No AP performance was reported.

\section{Further discussion}

In principle, AP flooding is expected to have benefits of polymer mobility control and soap-improved displacement efficiency. However, the field performance of the AP projects is mixed.

The number of field project is so small. This fact raises a question about the robustness of AP flooding. Alkaline reaction with crude oil can generate surfactant in situ. However, the amount of surfactant generated is little. For example, at maximum $0.1 \%$ concentration can be estimated from the Sheng et al. (2011) simulation data, and Sheng et al. (2011) showed that the maximum microemulsion saturation was about $4 \%$. Considering that a surfactant solution needs to be at an optimum salinity to perform, it can be seen that it is difficult to have the benefit of alkaline generated surfactant. This insignificant benefit may be proved by the fact that field alkaline projects did not show a high incremental oil recovery (Sheng 2015). Addition of alkali will reduce polymer solution viscosity. Probably, this negative effect will be more significant. Although Fig. 1 demonstrated the AP synergy from experimental data, more experimental data, theoretical analysis and simulation work are needed to verify the synergy.

Acknowledgments This work, especially field data collection part, was financially supported by the joint industry project (JIP), Chemical EOR Knowledge Database. The financial support from the member companies in this JIP is gratefully appreciated.

Open Access This article is distributed under the terms of the Creative Commons Attribution 4.0 International License (http:// creativecommons.org/licenses/by/4.0/), which permits unrestricted use, distribution, and reproduction in any medium, provided you give appropriate credit to the original author(s) and the source, provide a link to the Creative Commons license, and indicate if changes were made.

\section{References}

Al-Bahar MA, Merrill R, Peake W, Jumaa M, Oskui R (2004) Evaluation of IOR potential within kuwait. In: Paper SPE 88716 presented at the abu dhabi international conference and exhibition, Abu Dhabi, United Arab Emirates, 10-13 October

Bala GA, Duvall ML, Jackson JD, Larsen DC (1992) A flexible lowcost approach to improving oil recovery from a (very) small minnelusa sand reservoir in Crook County, Wyoming, paper SPE 24122 presented at the SPE/DOE Enhanced Oil Recovery Symposium, 22-24 April, Tulsa, Oklahoma, USA

Chen ZY (1994) Experimental study of AP flooding in Yangshamu Guan II upper group. Oil Gas Recover Technol 1(2):33-38

Chen Z-Y, Sun W, Yang H-J (1999) Mechanistic study of alkalinepolymer flooding in Yangsanmu Field. J Northwest Univ (Nat Sci Ed) 29(3):237-240 
Crestar (1991) Approval no. 4357A, Cessford Basal Colorado 'A' pool experimental alkaline/polymer flood, progress report, Crestar energy, January 1, 1991-December 31, 1991

Crestar (1992) Approval no. 4357, Cessford Basal Colorado 'A' Pool experimental alkaline/polymer flood, progress report, Crestar energy, January 1, 1992-December 31, 1992

David (1985) Approval no. 4263 and 2671C, David Lloydminister 'A' pool, progress report no. 3, Dome Petroleum Limited, August 1985-February 1986

David (1990) Approval no. 5353B, David experimental alkali/ polymer scheme, progress report no. 9, Amoco Canada Petroleum Company Ltd., March 1, 1990-August 31, 1990

Delamaide E, Bazin B, Rousseau D, Degre G (2014) Chemical EOR for heavy oil: the Canadian experience, paper SPE 169715 presented at the SPE EOR Conference at Oil and Gas West Asia, 31 March-2 April, Muscat, Oman

Doda A, Kotsuchibashi Y, Trivedi JJ, Narain R (2013) Investigation of alkali resistant polymer for improved heavy oil recovery, paper SPE 165514 presented at the SPE Heavy Oil ConferenceCanada, 11-13 June, Calgary, Alberta, Canada

Doll TE (1988a) Performance data through 1987 of the Isenhour Unit, Sublette County, Wyoming, Polymer-Augmented Alkaline Flood, paper SPE 17801 presented at the SPE Rocky Mountain Regional Meeting, 11-13 May, Casper, Wyoming

Doll TE (1988b) An update of the polymer-augmented alkaline flood at the Isenhour Unit, Sublette County, Wyoming, SPE Reservoir Engineering 3(2):604-608

Edinga KJ, McCaffery FG, Wytrychowski IM (1980) Cessford basal Colorado A reservoir caustic flood evaluation. J Pet Technol 32(12):2103-2110

Ehrlich R, Wygal RJ (1977) Interaction of crude oil and rock properties with the recovery of oil by caustic waterflooding. SPEJ (August), pp 263-279

Galas et al. (2012) Galas, C. Identification of enhanced oil recovery potential in Alberta phase 2 final report for energy resources conservation board. http://www.ags.gov.ab.ca/publications/pdf downloads/ercb-eor-report2.pdf. Accessed 25 Oct 2015

Han D (2001) Surfactant flooding: principles and applications. Petroleum Industry Press, pp 272-289

Housefly (1986) Approval no. 4065, Horsefly lake caustic-polymer pilot project lower Mannville pool, Technical Report, PanCanadian Petroleum Limited, January 20, 1986

Housefly (1987) Approval no. 4065, horsefly lake caustic-polymer pilot project lower Mannville pool, progress report No. 6, PanCanadian Petroleum Limited, July 1, 1987-December 31, 1987

Housefly (1989) Enhanced recovery week April 3, 1989, "Horsefy consumed caustic, waterflood may benefit"

Kang WL (2001) Study of chemical interactions and drive mechanisms in Daqing ASP flooding. Petroleum Industry Press

Kazempour M, Sundstrom EA, Alvarado V (2012) Effect of alkalinity on oil recovery during polymer floods in Sandstone. SPE Reserv Eval Eng 15(2):195-209

Krumrine PH, Falcone JS (1983) Surfactant, polymer, and alkali interactions in chemical flooding processes. Paper SPE 11778 presented at the SPE Oilfield and Geothermal Chemistry Symposium, Denver, 1-3 June

Krumrine PH, Falcone JS (1987) Beyond alkaline flooding: Design of complete chemical systems. Paper SPE 16280 presented at the
SPE International Symposium on Oilfield Chemistry, San Antonio, 4-6 February

Manji KH, Stasiuk BW (1988) Design considerations for Dome's David alkali/polymer flood. J Can Pet Technol 27(3):48-54

Mayer EH, Berg RL, Carmichael JD, Weinbrandt RM (1983) Alkaline injection for enhanced oil recovery - a status report. J Petrol Technol 35(1):209-221

O\&G J (1982) Steam dominates enhanced oil recovery. Oil Gas J 139-159

Pitts MJ, Wyatt K, Surkalo H (2004) Alkaline-polymer flooding of the David Pool, Lloydminster Alberta, paper SPE 89286 presented at the SPE/DOE Symposium on Improved Oil Recovery, 17-21 April, Tulsa, Oklahoma

Qiu Y, Chen Z, Xu S (1982) Waterflooding of channel Sandstone reservoirs, paper SPE 10559 presented at the International Petroleum Exhibition and Technical Symposium, 17-24 March, Beijing, China

Schultz WP, Roebuck IF, Dodge CF (1983) Enhanced oil recovery for the independent producer, Institute for the Study of Earth and Man at Southern Methodist University, Dallas, Texas

Shandrygin AN, Lutfullin A (2008) current status of enhanced recovery techniques in the Fields of Russia, paper SPE 115712 presented at the SPE Annual Technical Conference and Exhibition, 21-24 September, Denver, Colorado, USA

Sheng JJ (2011) Modern chemical enhanced oil recovery: theory and practice. Elsevier

Sheng JJ (2015) Status of alkaline flooding technology. J Petrol Eng Technol 5(1):44-50

Sheng D-C, Yang P-H, Liu Y-L (1994) Effect of alkali-polymer interaction on the solution properties. Petrol Explor Develop 21(2):81-85

Sheng JJ, Leonhardt B, Azri N (2015) Status of polymer-flooding technology. JCPT 54(2):116-126

Shupe RD (1981) Chemical stability of polyacrylamide polymers. J Petrol Technol 33(8):1513-1529

Sloat BF (1982) The Isenhour unit-a unique polymer-augmented alkaline flood, paper SPE 10719 presented at the SPE Enhanced Oil Recovery Symposium, 4-7 April, Tulsa, Oklahoma

Sloat BF, Fitch JP, Taylor JT (1972) How to produce more oil and more profit with polymer treatments, paper SPE 4185 presented at the SPE California Regional Meeting, 8-10 November, Bakersfield, California, USA

Wu Y, Dong M, Shirif E (2011) Study of alkaline/polymer flooding for heavy-oil recovery using channeled sandpacks. SPE Reser Eval Eng 14(3):310-319

Xu WD, Sun L, Pu WF, Zhao JZ, Xin J (2008) Effect of GH on AP solution flooding. J Southwest Petrol Univ (Sci Technol Ed) 30(4):151-153

Yang D, Wang J, Jing L, Feng Q, Ma X (2010) Case study of alkalipolymer flooding with treated produced water, paper SPE 129554 presented at the SPE EOR Conference at Oil and Gas West Asia, 11-13 April, Muscat, Oman

Zhang J, Wang K, He F, Zhang F (1999) Ultimate evaluation of the alkali/polymer combination flooding pilot test in XingLongTai Oil Field, paper 57291 presented at the SPE Asia Pacific Improved Oil Recovery Conference, 25-26 October, Kuala Lumpur, Malaysia 